\title{
Systematic Program for Destroying of Flies' Population in Poultry Farm under Battery Cage Management in Russia
}

\author{
Rinat Tuktarovich Safiullin*, Radmir Rinatovich Safiullin and Ekaterina Olegovna Kachanova \\ All-Russian Scientific Research Institute of Fundamental and Applied Parasitology of Animals and Plants named after K.I. Skryabin - Branch of the \\ Federal State Budget Scientific Institution «Federal Scientific Center - All-Russian Scientific Research Institute of Experimental Veterenari Medicina \\ K.I. Skryabin and Y.R. Kovalenko the Russian Academy of Sciences», 28, B. Cheremushkinskaya Street, Moscow, 117218, Russia
}

*Corresponding author's Email: safiullin_r.t@mail.ru; ORCID: 0000-0003-0450-5527

Received: 11 Oct. 2019

Accepted: 19 Nov. 2019

\begin{abstract}
Favorable conditions for development, reproduction, and accumulation of large amounts of zoophilous flies in commercial poultry farms are caused by incomplete compliance with veterinary and sanitary rules for growing in cage facilities. The purpose of the study was to test a systematic insecticidal program for destroying flies' populations using adulticide and larvicide drugs in poultry farms under battery cage management. The number of imago flies in hen houses was dynamically evaluated using flypapers, six flypapers in each hen house, situated in different levels above the floor. Flypapers were removed and the number of stuck insects was counted. The number of larvae was evaluated in dynamics by specimen testing from the floor area 10x10 cm, with weight of 3-5 g. The Quick Bayt WG 10\% was applied to destroy the imago of flies. Baycidal@ WP 25\% was used against larvae of flies. Complex insecticide program Quick Bayt WG 10\% + Baycidal® WP 25\% provided the opportunity to destroy flies, with a significant difference in intensefficacy, (98.3\% for adult flies and $99.8 \%$ for larvae). Furthermore, this program had a positive impact on economic indicators of meat production of broilers. The present study demonstrated high preventive efficacy and economical efficacy of complex program against flies under battery cage broiler management.
\end{abstract}

Key words: Adulticide, Economical Efficacy, Fly Larvae, Intensefficacy, Larvicide, Zoophilous Flies

\section{INTRODUCTION}

Poultry growing in premises which is free of endoparasites and ectoparasites is an important factor in improving national poultry breeding. Favorable conditions for development, reproduction, and accumulation of large amounts of zoophilous flies are due to the incomplete observance of veterinary and sanitary standards in commercial poultry housed in cage facilities. Several studies have established that flies are the carriers of infectious and parasitic diseases in humans, animals, and birds (Pokrovskiy and Zima, 1939; Veselkin, 1981; Kerbabaev, 2000).

The flies cause economic losses due to drop in egg production, reduction in chicken body weight gain, the premature slaughter of ill birds as well as damage to business reputation if fly larvae are founded in poultry and ready-to-cook foods (Safiullin et al., 2014).

For the proper management and successful protection against flies, it should be always remembered that the adult flies only include $15 \%$ of the population of flies, while larvae at different stages of development account for $85 \%$ of the population. For this reason, control of flies' population in poultry breeding requests simultaneous drug administration against adult and larval stages (Safiullin, 1995; Rules, 2002; Safiullin et al., 2011; Safiullin et al. 2017a; Safiullin, 2019). Hence, the aim of the present study was to evaluate the efficiency of complex insecticide (adulticide and larvicide) program to systematically eliminate flies' populations in broiler farms with the battery cage system.

\section{MATERIALS AND METHODS}

\section{Ethical approval}

The study was conducted in compliance with European Convention for the protection at vertebrate animals used for experimental and other scientific purposes (ETS 123, 1986) and the Russian Federation guidelines for good clinical practice (2003). Also, the current study was in accordance with the guidance for the 
experimental evaluation of new pharmacological substances (Habriev, 2005).

\section{Safety requirements}

Safety requirements, such as work clothing, gloves, and rubber shoes, were considered when using insecticides. The drugs were applied in the houses during the preparation for birds' settlement.

\section{Experimental design}

The trial test was conducted in a poultry farm in the Vladimir Region, Russia, from July to September 2018. Laboratory studies were conducted in All-Russian Scientific Research Institute of Fundamental and Applied Parasitology of Animals and Plants named after K.I. Skryabin, Moscow, Russia.

Studies were carried out in two similar hen houses, experimental and control, with a capacity of 84,445 birds. All hen houses were similar, equipped with three-storied battery cages installing in six levels and excrement channels along all hen house. Broiler chicken cross "Cobb-500" was in the hen houses when placement: 41,780 and 42,665 birds in experimental and control henhouse, respectively (Table 1). The average weight of broilers was $38 \mathrm{~g}$ in both henhouses when placement. Insecticide dressings of hen-houses and sanitary preparation of buildings were conducted according to the established procedure before the new batch of birds were stocked.

The primary insecticide program against flies in farms was applied using an adulticide drug on the basis of fipronil with a recommended dose. Adulticide agent of Quick Bayt® WG 10\% (Bayer, Germany) was administered against adult flies in experimental henhouses. The drug dosage was selected according to the floor area. Two and one-half grams of Quick Bayt ${ }^{\circledR}$ WG $10 \%$ diluted in $20 \mathrm{ml}$ of water per $1 \mathrm{~m}^{2}$ of the floor. Treatment solution was applied to vertical surfaces by spraying using sprayer Gloriya (Gloria $\mathrm{GmbH}$ ) with effective pressure, not more than 1 bar. Totally, about $30 \%$ of walls area and other vertical surfaces where flies prefer to be (warm sunny walls, ventilation openings, window frames, and ceiling lights) were dressed by a vertical zigzag method up to a height of $2.5 \mathrm{~m}$.

Floor dressing by larvicide drug of Baycidal ${ }^{\circledR}$ WP $25 \%$ (Bayer, Germany), with a dose of $2 \mathrm{~g}$ per $1 \mathrm{~m}^{2}$ floor surface, was performed immediately following wall dressing by the drug Quick Bay WG 10. Treatment solution was applied with the help of large-drop spray using DUK (Komarov's disinfecting units, GAM, Russia) at a rate of $200-300 \mathrm{ml}$ per $1 \mathrm{~m}^{2}$ of the floor and at proper places for flies' reproduction such as excrement channels, excrement hollows, carriers, and other places where rests of food, excrements may accumulate.

The number of imago flies in hen-houses was dynamically evaluated using flypapers (flycatcher "Mukholov-Kapkan", Avantari, Russia), six flypapers in each hen-house situated in different levels above the floor. After 24 hours, flypapers were removed and the number of stuck insects was counted. For the dynamic evaluating amount of larvae, the specimens obtained from the floor, with a surface area of $10 \times 10 \mathrm{~cm}$ and weight of 3-5 g. In addition, contents of dung channels under battery cages were sampled using a special sampling device. Six aliquots were taken from each hen-house (Figures 1 and 2). At first, feces sampling was performed at the end of growing period of previous bird batch, in 24 hours after complex insecticide program, and then weekly for the entire duration of broiler growing.

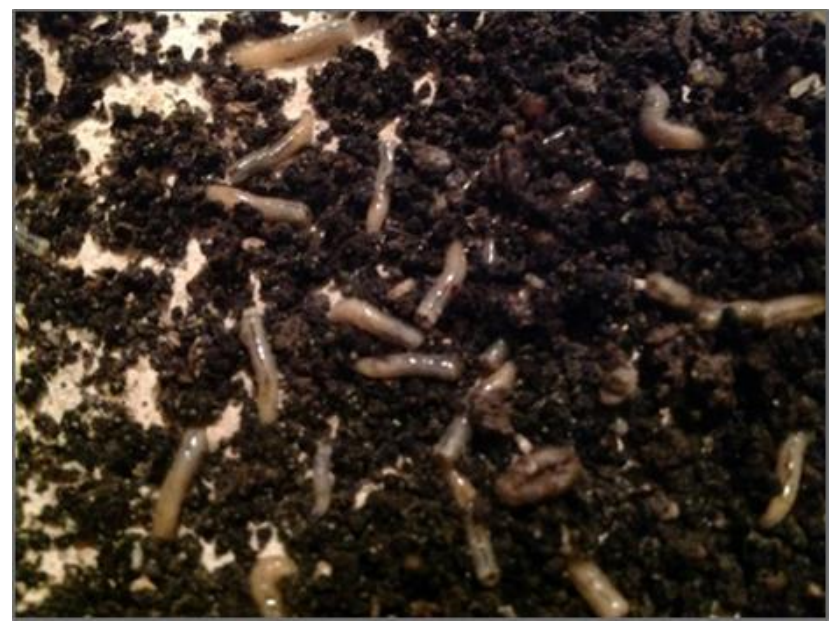

Figure 1. Larvae and pupae of flies from the passage between the batteries

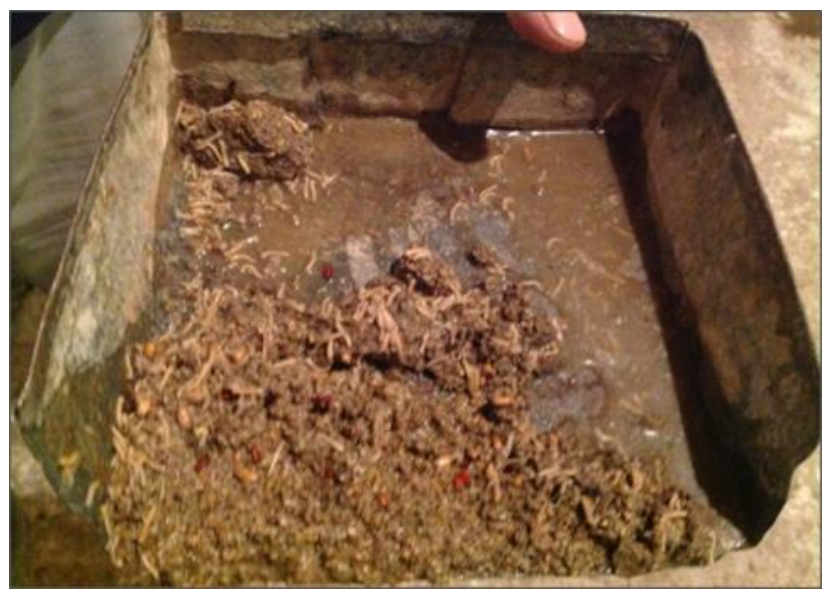

Figure 2. Larvae and pupae of flies from the litter channel 
In total, flies were counted seven times during the study. The species of flies was established using the "Key to insects of the European part of the USSR" (Shtakelberg, 1969), "Key to insects of the European part of the USSR" (Bei-Bienko, 1970), the manual "Synanthropic twowinged fauna USSR" (Shtakelberg, 1956) and by using Zeiss "Primo Star" microscope.

The percentage of chickens' survival was determined by the ratio of the final number of birds to the initial number. The productivity and economic efficiency were evaluated by the mortality rate, average daily weight gain, and broiler feed costs.

\section{Statistical analyses}

Data on the number of imago and larvae flies were subjected to statistical analysis according to the method described by Plokhinsky (1978). Statistical analysis was performed using SAS/Stat software, version 9 (SAS Institute Inc., USA). Differences were considered to be significant for $\mathrm{p}$-value $<0.05$.

\section{RESULTS AND DISCUSSION}

Two weeks before the end of the previous broiler party, the average number of imago flies and larvae was 1040 specimens in each flypaper and 145 specimens in each aliquot, respectively in henhouses where recommended dose of fipronil drug was administrated. This indicated a high risk for the farm.

This study indicated the following species: Musca domestica domestica (dominance index $93.38 \%$ ), Protophormia terrae-novae (dominance index $4.19 \%$ ) and Licilla sericata (dominance index $2.43 \%$ ) in the hen houses.

The average amount of adult flies decreased sharply in experimental hen-house (18 specimens per one flypaper) after dressing by the drug "Quick Bayt WG $10 \%$ " compared to the first measurement. "Quick Bayt WG 10\%" in which imidacloprid (neonicotinoids group) is an active ingredient, indicated insecticidal activity against adult flies. At the same time, the number of imago flies was 1015 specimens after routine disinfection by fipronil in the control henhouse.

All aliquots taken from the floor and excrement channels in experimental henhouse were free of flies' larvae after dressing by the drug Baycidal WP $25 \%$. Baycidal WP $25 \%$ has a larvicidal effect, interrupts the process of larval development, result in death before transformation into the adult stage. The active ingredient of triflumuron blocks chitin generation, which may be necessary for growing processes during larval molting in passing from one stage to another. As well as triflumuron has the ovicidal effect that leads to death of embryos and larvae hatched from the ootids (Howard and Wall, 1995). Moreover, it has been noted that triflumuron has a sterilization effect on adult flies (Broce and Gonzaga, 1987). Adult pubescent females failed to generate viable offspring after applying "Baycidal WP 25\%". Also, this drug showed high efficiency against larvae of flies in pigsties (Safiullin et al., 2016).

Weekly studies showed a slightly residual number of adult flies and a complete absence of larvae during five weeks in the experimental henhouse. In the experimental henhouse, the number of flies and larvae remained very low close to zero during the whole broiler rearing period (38 days). Sustained duration of action of adulticide "Quick Bayt WG 10\%" and larvicide "Baycidal WP 25\%" did not give the opportunity to larvae to develop during the whole rearing period thus a significant reduction $(\mathrm{p}<0.05)$ in flies population was observed (Figures 3 and 4). Complex insecticide program "Quick Bayt WG 10\%" + "Baycidal ${ }^{\circledR}$ WP $25 \%$ " provided the opportunity to destroy flies, with a significant difference in intensefficacy ( 98.3 $\%$ for adult flies and $99.8 \%$ for larvae).

In control henhouse where larvicide was not applied and adulticide of fipronil was only used, larvae were recorded in a large number in excrement channels under cage batteries and on the floor where poultry feed and excrements were available. Consequently, flies' population was very high at these places and reduced slightly at the end of the period with the lowering of air temperature. Significant reduction in flies and larvae number in experimental henhouse during the whole cycle of growth showed a positive influence on chickens survival, weight gain, and feed-gain, which are consistent with data from other studies (Tashbulatov et al., 2016; Al Thabiani, 2017). Broiler chickens, which were grown in experimental henhouse, where larvicide and insecticide program had been conducted, exhibited better conditions for growth by reduction of stress caused by troublesome flies under the equal conditions with control henhouse in terms of environment, feeding, and drinking. In addition, it had a positive impact on productive economic parameters.

Chickens' survival throughout the growing cycle in experimental hen-house was $95.5 \%$, and in control henhouse was $93.6 \%$. The average daily weight gain of chickens in experimental and control hen-house was 58.6 $\mathrm{g}$ and $51.4 \mathrm{~g}$, respectively $(\mathrm{P}<0.05)$ (Table 1$)$.

Therefore, broiler chickens from the experimental hen-house where the complex insecticide program was 
conducted, had $14 \%$ higher productivity compared to control where fipronil was only used as an insecticide.

The average slaughter weight was $2226.8 \mathrm{~g}$ and $1953.2 \mathrm{~g}$ in experimental and control hen-houses, respectively. The effective killing percentage was $73.7 \%$ in both hen-houses. In monetary terms, a carcass from experimental group cost 268.2 Russian Ruble (RUB) and from control group cost RUB 253.3. The feed conversion ratio in the experimental and control group was $1.91 \mathrm{~kg}$ and $1.99 \mathrm{~kg}$, respectively.

The cost of destroying flies and larvae in control where fipronil was administered was 8640 RUB, which was lower compared to the experimental hen house 12364 RUB. However, production and destroying efficacy was lower in the control house.

The economic effect of using complex insecticide program against adult flies and larval compared to fipronil drug was determined. The economic effect of administration of complex insecticide program against adult and larval flies was 14.9 RUB /one broiler, and 582.05 thousand RUB on all broilers in the experimental hen house.

Systematic program for destroying flies' population using adulticide and larvicide drugs in poultry farms under battery cage management provided high efficacy against adult flies and larvae. The average number of adult flies per 1 flycatcher was 18 specimens in the experimental henhouse for a five-week period after destroying, while in the control hen house was 1044 specimens. A similar result was for the larvae of flies. The number of larvae of flies after processing with "Baycidal ${ }^{\circledR}$ WP 25\%" at different periods of research was as follows: during two weeks after processing, zero larvae; during the third and fourth weeks, one larva; and in fifth week zero larva. The average number of larvae was 0.3 specimens in the experimental henhouse. However, in the control henhouse there were 102 specimens. The present results are consistent with data of other researchers, which tested the combined use of Sulfak and Baicidal against adult flies and larvae in the pigsty (Safiullin and Ageev, 2016). Data are also consistent with the work of authors who evaluated Solfak with Baicidal in broiler farms with cage system (Safiullin et al. 2017b).

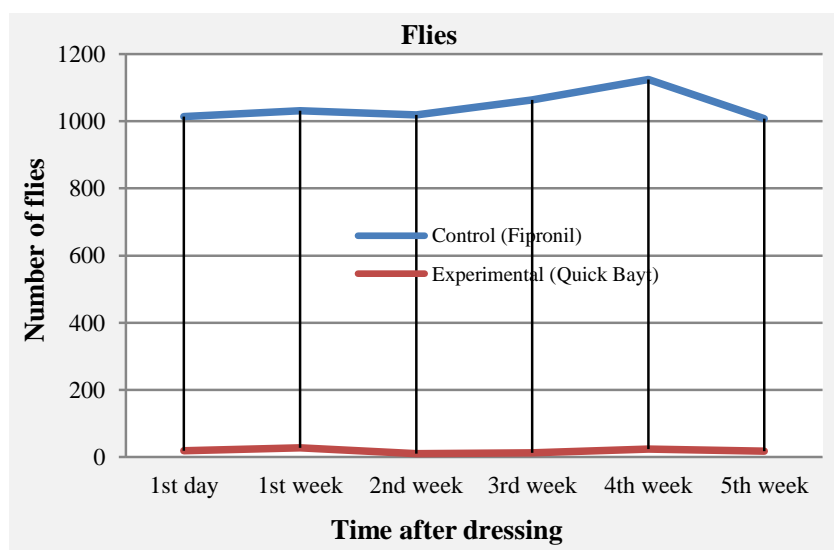

Figure 3. The number of adult flies during the five-week study period in the experimental and control henhouses, Russia

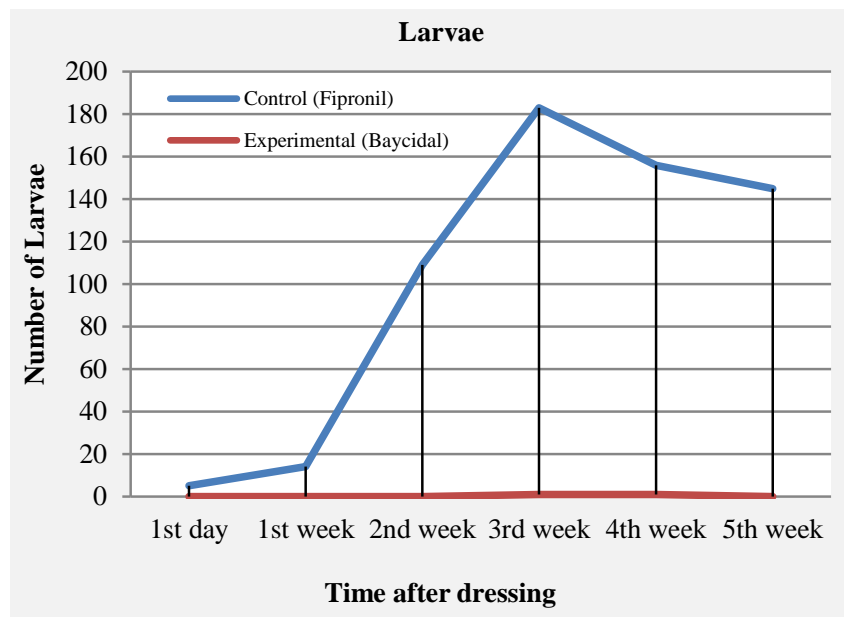

Figure 4. The number of larvae during the five-week study period in the experimental and control henhouses, Russia

Table 1. Effects of insecticides application against flies on economic and production parameters in broiler farms under battery cage management, Russia

\begin{tabular}{|c|c|c|c|c|c|c|c|c|c|}
\hline $\begin{array}{l}\text { Henhouses } \\
\text { (groups) }\end{array}$ & $\begin{array}{l}\text { Broilers' } \\
\text { number } \\
\text { when } \\
\text { placement }\end{array}$ & $\begin{array}{c}\text { The } \\
\text { number } \\
\text { of dead } \\
\text { Chicken }\end{array}$ & $\begin{array}{c}\text { Chicken's } \\
\text { survival } \\
(\%)\end{array}$ & $\begin{array}{c}\text { Average } \\
\text { daily } \\
\text { weight gain } \\
\text { (g) }\end{array}$ & $\begin{array}{c}\text { Average } \\
\text { slaughter } \\
\text { weight (g) }\end{array}$ & $\begin{array}{c}\text { Killing } \\
\text { percentage } \\
(\%)\end{array}$ & $\begin{array}{c}\text { Cost per } \\
\text { kilogram } \\
\text { of carcass } \\
\text { (RUB) }\end{array}$ & $\begin{array}{c}\text { Feed for an } \\
\text { increase of } \\
\text { one kg of } \\
\text { body weight } \\
\text { (kg) }\end{array}$ & $\begin{array}{c}\text { Expenditures } \\
\text { connected with } \\
\text { disinfestation } \\
\text { of } 1 \text { hen-house } \\
\text { (RUB) }\end{array}$ \\
\hline Experimental* & 41780 & 2716 & 95.5 & $58.6 \pm 1.67$ & 2226.8 & 73.7 & 268.2 & 1.91 & 12364 \\
\hline Control** & 42665 & 3584 & 93.6 & $51.4 \pm 1.84$ & 1953.2 & 73.7 & 253.3 & 1.99 & 8640 \\
\hline \multicolumn{5}{|c|}{ Statistical significance } & \multicolumn{2}{|c|}{$\mathrm{p}<0.05$} & & & \\
\hline
\end{tabular}

* Insecticide program: Quick Bayt WG (water-soluble granules) 10\% + "Baycidal WP (water-soluble powder) 25\%; ** Adulticide drug on the basis of fipronil 


\section{CONCLUSION}

In conclusion, the systematic program for destroying flies' population using an adulticide and larvicide drugs in poultry farm under battery cage management provided almost complete extermination of adult flies and larvae in difficult production conditions.

\section{DECLARATIONS}

\section{Acknowledgments}

We thank veterinarian experts of the poultry farm of the Vladimir Region which took an active part in conduction of these studies. Also we thank Bayer's employees for providing drugs for research. This study was supported by the All-Russian Scientific Research Institute of Fundamental and Applied Parasitology of Animals and Plants named after K.I. Skryabin.

\section{Authors' contributions}

Rinat Tuktarovich Safiullin designed the performed the experiments. Radmir Rinatovich Safiullin and Ekaterina Olegovna Kachanova analyzed the results, drafted and revised the manuscript. Finally, all authors read and approved the final manuscript and consent to publish in JWPR.

\section{Competing interests}

The authors have declared that they have no competing interests.

\section{REFERENCES}

Bei-Bienko GYA (1970). The general entomology, Moscow, p.346.

Broce AB and Gonzaga VG (1987). Effects of substituted benzylphenols and triflumuron on the reproduction of the face fly (Diptera: Muscidae). Journal of Economic Entomology, 80(1): 37-43. DOI: https://doi.org/10.1093/jee/80.1.37

Al Thabiani A (2017). Insecticidal activity of three insect growth regulators towards the dengue and Zika virus vector Aedes aegypti in Saudi Arabia. Journal of Entomology and Zoology Studies, 5(1):36-38. Available at: https://pdfs.semanticscholar.org/3220/b3fdc4aa673b6274262f3 a712f9896d1b840.pdf

Habriev RU (2005). The Guidance to Experimental (Preclinical) Studying of New Pharmacological Substances, Moscow, p. 832.

Howard J and Wall R (1995). The effects of triflumuron, a chitin synthesis inhibitor, on the housefly, Musca domestica (Diptera: Muscidae). Bulletin of Entomological Research, 85(1): 71-77. DOI: https://doi.org/10.1017/S0007485300052032

Kerbabaev EB, Vasilevich FI and Kataeva TS (2000). Arthropodosis of live-stock animals, Moscow, p.137. Available at: https://search.rsl.ru/ru/record/01000653425
Plokhinskiy NA (1978). Mathematical methods in biology, Moscow, p. 266. Available at: https://www.libex.ru/detail/book512589.html

Pokrovskiy SN and Zima GG (1939). Flies as carriers of worms in vivo. Medical Parasitology, 7: 262-264.

Rules for conducting disinfection and disinvasion of state veterinary supervision objects (2002), Moscow, p. 73. Available at: http://docs.cntd.ru/document/420258792

Safiullin RT (1995). Efficiency of sebacil in cases of parasitic diseases of animals. Journal of Veterinary, 5: 37-39.

Safiullin RT, Novikov PV and Leonteva OV (2011). Draker 10.2 is the new long-acting insecticide. Journal of Veterinary, 5:11-15. Available at: https://elibrary.ru/item.asp?id=16443783

Safiullin RT, Novikov PV and Tashbulatov AA (2014). Costeffectiveness insecticide program against flies in industrial poultry. Theory and practice of parasitic disease control: Collection of Scientific Articles adapted from the International Scientific Conference, 15: 275-279. Available at: https://www.vniigis.ru/1_dlya_failov/TPB/Vniigis_2014_konfe renciya.pdf

Safiullin RT and Ageev IS (2016). The combined use of Sulfak and Baicidal against flies in the mother barn. Theory and practice of parasitic disease control: Collection of Scientific Articles adapted from the International Scientific Conference, 17: 418422. Available at: https://www.vniigis.ru/1_dlya_failov/TPB/Vniigis_2016_konfe renciya.pdf

Safiullin RT, Safiullin RR and Novikov PV (2017). The background number of adults of flies and their larvae in a poultry farm with a broiler cage. Theory and practice of parasitic disease control: Collection of Scientific Articles adapted from the International Scientific Conference, 18: 427-431. Available at: https://www.vniigis.ru/1_dlya_failov/TPB/arkhiv/2017.pdf

Safiullin RT (2019). Parasitic diseases of birds, means and methods of control, Moscow, p.260.

Shtakelberg AA (1956). Synanthropic two-winged fauna USSR, Leningrad, p.164.

Shtakelberg AA (1969). Key to insects of the European part of the USSR Leningrad, p.807.

Safiullin RT, Ageev IS, Oleinikova VP and Saveljeva OA (2016). The effectiveness of Solfac and Baycidal against flies and their larvae in the pigsty of the liquor. Abstracts of XII-th European multicolloqium of parasitology: 9.25. Available at: http://congress.utu.fi/emop2016/index.php

Tashbulatov AA, Safiullin RT and Gavrilova TV (2016). Comprehensive cleaning, disinvasion equipment and facilities in the broiler poultry industry. Journal of Veterinary, 5: 39-41. Available at: https://elibrary.ru/item.asp?id=26561187

Veselkin GA (1981). Zoophilous flies and control measures against them. Journal of Veterinary, 7: $24-27$. 